\title{
The Insurance Coverage Paradox- Characterizing Outcomes Among Dual-Eligible Hemorrhagic Stroke Patients
}

Youry S Pierre-Louis ( $\sim$ youry_pierre-louis@brown.edu )

Brown University Warren Alpert Medical School https://orcid.org/0000-0003-1145-4422

Krissia M. Rivera Perla

Brown University Warren Alpert Medical School

Giancarlo Medina Perez

Brown University Warren Alpert Medical School

Skenda Jean-Charles

Brown University Warren Alpert Medical School

Oliver Y. Tang

Brown University Warren Alpert Medical School

Chibueze A. Nwaiwu

Rhode Island Hospital

Robert J. Weil

Rhode Island Hospital

Nish Shah

Rhode Island Hospital

Daithi S. Heffernan

Rhode Island Hospital

Carla C Moreira

Rhode Island Hospital

\section{Research article}

Keywords: Dual-eligible, Brain Injury, Intracranial Hemorrhage, Disparities, Socioeconomic status

Posted Date: June 29th, 2021

DOI: https://doi.org/10.21203/rs.3.rs-659199/v1

License: (c) (i) This work is licensed under a Creative Commons Attribution 4.0 International License.

Read Full License 
Version of Record: A version of this preprint was published at Journal of Clinical Neuroscience on March 1st, 2022. See the published version at https://doi.org/10.1016/j.jocn.2021.12.023. 


\section{Abstract}

Background: Socioeconomic factors, such as insurance status, have been shown to affect outcomes following emergency injuries. Dual-eligible beneficiaries, receiving both Medicare and Medicaid, constitute a vulnerable population. There is a lack of data on the impact of dual-eligible status on hemorrhagic stroke outcomes. The aim of our study was to compare hemorrhagic stroke outcomes among dualeligible patients compared to Medicare, Medicaid, privately insured, and no charge (free or charity) patients.

Study Design: We conducted a 10-year span retrospective analysis of the National Inpatient Sample. Adult patients who were emergently hospitalized for intracranial hemorrhage were included. Multivariable logistic regression was used to adjust for confounders. Primary clinical outcomes of interest included mortality (in-hospital), complications (any), and favorable discharge (home/home with services).

Results: A total of 410,621 patients met inclusion of which $6.8 \%$ were dual-eligible. Dual-eligibles had higher odds of in-hospital mortality compared to no-charge (adjusted odds ratio (aOR) $=1.61,95 \% \mathrm{Cl}=$ [1.04 - 2.49]) and increased odds of complications compared to Medicaid (aOR=1.23 [1.11 - 1.37]) and privately insured patients $(\mathrm{aOR}=1.19[1.11-1.28])$, both $p<0.001$. Dual-eligibles had lower odds of favorable discharge compared to all other groups (all $p<0.001$ ), and underwent shorter lengths of stay, an $18 \%$ decrease, compared to Medicaid patients $(p<0.001)$. Inflation adjusted admission costs among dualeligibles were $24 \%$ lower compared to Medicaid patients $(p<0.001)$, amounting to a $\$ 3,684$ decrease in cost.

Conclusions: Dual-eligible beneficiaries experience unique health disparities from lower odds of favorable discharge to increased odds of complications and in-hospital mortality compared to other insured and uninsured groups. There is a need to uncover and address unknown sources of disparities to improve emergency treatment of hemorrhagic stroke among dual-eligibles.

\section{Key Points}

Dual-eligible patients following emergent hemorrhagic stroke had increased adverse outcomes compared to other insured and uninsured groups. Dual-eligible patients had lower odds of favorable discharge and increased odds of complications and in-hospital mortality.

\section{Introduction}

Globally, cerebrovascular accident (CVA) or more commonly known as stroke, is the second leading cause of death [1]. Stroke can be categorized into two subtypes: ischemic stroke and hemorrhagic stroke [2]. Of the stroke subtypes, hemorrhagic stroke contributes to $10 \%-20 \%$ of annual strokes [3]. Hemorrhagic stroke occurs due to rupture of blood vessels; furthermore, hemorrhagic stroke can be further divided into intracerebral hemorrhage (bleeding into brain parenchyma) and subarachnoid hemorrhage (hemorrhage 
into the subarachnoid space). The progression of intracerebral hemorrhage is associated with worse prognosis $[3,4]$. Thus, early diagnosis and treatment are key factors in increasing survival [4].

Prior studies have described the negative impact of health disparities on the incidence of hemorrhagic stroke among patients from lower socioeconomic status and those who are uninsured $[5,6]$. Moreover, it has been reported that patients with lower socioeconomic status are more likely to have severe morbidity and higher rates of mortality [5]. Additionally, socioeconomic status and insurance eligibility have been strongly associated with influencing discharge disposition after neurological emergencies [7]. Patients with either Medicare or Medicaid have been reported to have worse outcomes compared with privatelyinsure patients. Similarly, significant increases in mortality, functional status, discharge disposition, and quality of care measures have been reported in Medicare, Medicaid, and uninsured patients compared to privately insured patients after intracerebral hemorrhage [8]. Dual-eligible beneficiaries, who are often elderly, physically disabled, and/or mentally disabled, receive both Medicare and Medicaid, and constitute an especially vulnerable population [9-11].

Insurance-specific differences in outcomes among patients with stroke have been documented. Shen et al [12]. specifically analyzed disparities in neurological impairment following stroke among uninsured patients and privately insured patients and found a much higher risk of mortality among those who are uninsured. This highlights the discrepancies in favorable outcomes and the importance of insurance status as a barrier to comprehensive treatment after a stroke. While there are prior studies comparing health outcomes by insurance status, there is a lack of literature comparing differences in health outcomes, specifically among hemorrhagic stroke, between patients with single-payer insurance status versus dual-eligible beneficiaries. Our study sought to characterize these outcomes among dual-eligible beneficiaries compared to Medicare-only, Medicaid-only, privately insured, and no charge patients.

\section{Methods}

Data Source: We queried the National Inpatient Sample, a publicly available all-payer inpatient care database, from 2000 to 2011. The National Inpatient Sample, established by the Healthcare Cost and Utilization Project (HCUP), includes individual inpatient admission data such as healthcare utilization, hospitalization charges, and clinical outcomes information. Sampling approximately $20 \%$ of all inpatient admissions, the National Inpatient Sample is the largest publicly available all-payor inpatient database in the United States [13]. Due to data restructuring in 2012, the National Inpatient Sample stopped reporting multiple insurance payors therefore, we were unable to identify dual-eligibles beyond 2011.

Patient selection: We conducted a 10-year span cross-sectional query of the National Inpatient Sample for all adult 18 years or older patients with brain hemorrhage using International Classification of Disease, 9th revision, Clinical Modification (ICD-9-CM) diagnosis codes (Supplemental Table 1). Furthermore, only emergent or urgent admissions from states reporting multiple insurance payors were included. Admissions were categorized as epidural, subdural, subarachnoid, or intracerebral hemorrhage (Supplemental Table 1). We also noted whether the patient received a cranial procedure or not during their 
inpatient admission (Supplementary Table 2). Patients without insurance information were excluded from further study. We collected patient demographic characteristics such as sex, age, race, median household income quartile, insurance type, All Patient Refined Disease-Related Group (APR-DRG) risk of mortality, APR-DRG severity of illness, hospital urban location, and hospital region [14]. Patient admissions were categorized based on insurance status: Dual-eligible, Medicare, Medicaid, Privately insured, and no charge (free or charity). To accommodate large amounts of missing race data, we used multinomial logistical regression to impute missing values as prescribed by HCUP [15].

Outcomes: In our final cohort of emergent brain hemorrhage patients meeting study criteria, the primary outcomes of interest included; mortality (in-hospital), complications (any), and favorable discharge (home/home with services). Secondary outcomes of interest included; Clavien-Dindo Classification grade, length of stay, and inpatient cost. Complications were characterized as experiencing any complication during inpatient admission (Supplementary Table 3). Favorable discharge was considered as discharge to home or home with services. Clavien-Dindo Classification grade, a complication severity scoring system, was assigned using methodology from Hall et al [16] and Dindo et al [17]. Length of stay was calculated as the number of days from admission to discharge. Lastly, admission cost was calculated using HCUP provided cost-to-charge ratios that were subsequently adjusted for inflation using the Consumer Price Index [18] and the year 2011 as reference.

Statistical Analysis: Stata/SE 15.1 was used for statistical analysis. We applied survey weights using svy commands in accordance with previously published HCUP methodology [19]. Multivariable logistic regression was used for binary outcomes. We controlled for age, sex, race, median household income quartile, APR-DRG risk of mortality (mortality model only), APR-DRG severity of illness (all models except mortality), hemorrhage type (epidural, subdural, subarachnoid, and intracerebral), procedure (yes or no), hospital urban location, and hospital region (Northwest, Midwest, South, and West). Gamma regression with a log-link function was used for continuous right-skewed variables such as length of stay and inflation-adjusted admission cost. -coefficients pertaining to percent change (ex. -coefficient $=1.05$ equates to a $5 \%$ increase) were reported for length of stay and admission cost. All model covariates were chosen prior to any model building using existing clinical knowledge. We were careful to include potential confounders and predictors and exclude collinear variables while avoiding overfitting our model. An alpha level of significance of 0.05 was used.

\section{Results}

Population Characteristics: Among the 410,620 adult emergent brain hemorrhage patients included in the study, $1.6 \%$ were epidural, $54.1 \%$ subdural, $27.7 \%$ subarachnoid, and $16.6 \%$ were intracerebral. The private insurance cohort was the largest (55.0\%), followed by Medicare (30.2\%). A total of 28,114 (6.8\%) dualeligibles met inclusion; female patients comprised $59.4 \%$ of the population and dual-eligible patients were on average older (Mean=73.4 years, Standard Deviation (SD)=14.9) than all other groups except Medicare (77.9 years, SD=11.2) (Table 1). The dual-eligible group had the highest proportion of Black patients after Medicaid (14.9\% and $21.9 \%$ respectively) and a higher proportion of patients in the bottom $25^{\text {th }}$ percentile 
of median household income after Medicaid patients (39.6\% and $42.4 \%$ respectively). Medicare and Medicaid patients had the highest proportion of patients characterized as extreme APR-DRG Risk of Mortality (16.3\% and 16.6\%), and Medicaid the highest percentage of admissions in the extreme APRDRG severity of illness category (22.4\%) (Table 1 ).

Primary Outcomes: Medicare patients had the highest proportion of in-hospital mortality $(n=16,046$; 13.0\%) (Table 2). After adjustment, dual-eligibles had significantly higher odds of in-hospital mortality compared to no-charge (free or charity) patients (adjusted odds ratio $(\mathrm{aOR})=1.61,95 \% \mathrm{Cl}=[1.04-2.49]$ ). However, there was no significant difference in odds of in-hospital mortality when comparing dualeligibles to Medicare and Medicaid patients (Table 3). Overall, dual-eligible patients had the highest proportion of complications $(n=7,768 ; 27.6 \%)$ compared to all other groups (Table 2). Dual-eligibles had significantly increased odds of complication compared to Medicaid (aOR=1.23, 95\% Cl= [1.11 - 1.37]) and privately insured patients $(\mathrm{aOR}=1.19,95 \% \mathrm{Cl}=[1.11-1.28])$, both $\mathrm{p}<0.001$. Lastly, dual-eligibles had significantly lower odds of favorable discharge (discharge home or home with services) compared to all other groups, all $p<0.001$ (Table 3).

Secondary Outcomes: The most common Clavien-Dindo Classification grade was grade II for all groups except Medicaid and no-charge patients who had the highest percentage of patients categorized as grade IV ( $n=3,186 ; 10.8 \%$ and $n=264 ; 8.6 \%$, respectively) (Table 2). Compared to Medicaid and privately-insured patients, dual-eligibles had significantly increased odds of being in a higher Clavien-Dindo Classification grade (Medicaid: aOR=1.21, 95\% Cl= [1.08 - 1.35] and private: $\mathrm{aOR}=1.21,95 \% \mathrm{Cl}=[1.13-1.30]$ ), both $p<0.001$ (Table 3). The mean length of stay was the longest among Medicaid (mean=11.0 days) and nocharge patients (mean $=8.0$ ) (Table 2). Dual-eligibles underwent a shorter length of stay, an $18 \%$ decrease, compared to Medicaid patients ( - Coefficient $=0.82,95 \% \mathrm{Cl}=[0.78-0.86], \mathrm{p}<0.001$ ) however, there were no significant differences in lengths of stay between dual-eligibles and the other groups (Table 3). Finally, dual-eligibles had significantly lower inflation-adjusted admission costs compared to all other groups, all $p<0.001$ except Medicare $(p<0.05)$ (Table 3). The average admission cost for dual-eligibles was $\$ 13,948$ compared to $\$ 23,546$ for Medicaid patients (Table 2). After adjustment, dual-eligibles had inflationadjusted admission costs that were $24 \%$ lower compared to Medicaid patients ( - Coefficient $=0.76,95 \%$ $\mathrm{Cl}=[0.73-0.80], \mathrm{p}<0.001)$, amounting to a $\$ 3,684$ decrease in cost (Table 3$)$.

\section{Discussion}

This retrospective study of emergent hemorrhagic stroke patients found increased odds of in-hospital mortality for dual-eligible patients compared to no-charge patients and higher odds of complication (any) for dual-eligible patients compared to Medicaid and privately insured patients. Notably, dual-eligible patients had decreased odds of favorable discharge (home/home with services) compared to all other groups. Regarding secondary outcomes, dual-eligibles had increased odds of being in a higher ClavienDindo Classification grade compared to Medicaid and privately insured patients. Interestingly, dualeligible had decreased hospital length of stay compared to Medicaid patients and deceased inflationadjusted admission costs compared to all other insurance groups. To the best of our knowledge, our 
study is the first to focus on and characterize dual-eligible patient outcomes after emergent hemorrhagic stroke.

The present study found increased odds of in-hospital mortality among dual-eligibles compared to nocharge patients after adjustment, but no difference when compared to Medicare and Medicaid patients. Interestingly, James et al. [7] and Lai et al. [20] found that mortality risk was higher for hemorrhagic stroke patients with Medicaid, Medicare, and no insurance, compared to Private insurance [7]. Additionally, Shen et al. [12] found that out of all insurance groups, uninsured patients had the highest mortality risk for hemorrhagic strokes with a $24 \%$ higher mortality risk for uninsured compared to privately insured patients. Some of these findings may be explained by differences in treatment allocation by insurance status. For example, Hobson et al. [21] reported that mortality was more than twice as likely for patients with no surgical treatment after subarachnoid hemorrhage compared to those who received surgery. The same study found Medicare patients were significantly less likely to receive surgical treatment. McCutcheon et al. [22] found a similar finding where uninsured patients demonstrated both a reduced likelihood of receiving a craniotomy for intracranial hematomas and an increased riskadjusted mortality rate relative to insured patients.

The lack of difference between mortality rates for dual-eligible compared to Medicare patients is likely explained by the similar ages in both populations. With increased age as a risk factor for mortality, it is important to note that Medicare and dual-eligible patients in our study were on average older than all other groups [23]. Additionally, Medicare patients in our study had the second-highest proportion of patients characterized as extreme APR-DRG Risk of Mortality signaling increased comorbidities. The nonsignificant difference between mortality rates for dual-eligible compared to Medicaid patients is likely multifactorial but is supported by the finding that the socioeconomic status of patients can influence mortality risk after stroke. For example, Kapral et al. [5] found that each $\$ 10,000$ increase in median neighborhood income was associated with a $9 \%$ reduction in the hazard of death at 30 days for acute stroke patients.

Regarding the relationship between complications and insurance status, one study of traumatic brain injury patients by Schiraldi et al. [9] found that Medicaid patients were 1.78 times more likely to experience complications than commercially insured patients. Additionally, specific to subarachnoid hemorrhage, Dasenbrock et al. [24] found that Medicaid payer status was an independent predictor of developing Clostridium difficile infection which has been associated with increased hospital stay and a nonroutine hospital discharge. These results are consistent with our study, which found a higher incidence of complications in dual-eligible patients compared to privately insured patients. However, our study also found that dual-eligibles had significantly higher odds of complications compared to Medicaid, with dual-eligibles having the highest proportion of complications.

Overall, our study found significantly decreased odds of favorable discharge (home/home with services) among dual-eligibles compared to all other insurance groups. Notably, dual-eligibles in our study experienced increased odds of complications, which may in part explain this trend. A systematic review 
analyzing predictors of discharge location for patients post-traumatic brain injury reported increasing age, white and non-Hispanic race/ethnicity, insurance coverage, and more severe injury as predictors of discharge to a setting with rehabilitation services versus discharge to home [25]. Results of the James et al, [7] analysis demonstrated that both Medicare and Medicaid hemorrhagic stroke patients were less likely to be discharged home in comparison to privately insured individuals. Conversely, Lai et al. [20] found that Medicaid and uninsured patients had a reduced odd of non-routine discharge despite longer hospital stays. A study by Strickland et al. [26] reported that when comparing patients treated for subarachnoid hemorrhage in a university hospital with a safety net county hospital, the safety net county hospital patients were 3.73 times more likely to be discharged with poor modified Rankin Scale scores and 3.08 times more likely to be discharged with poor Glasgow Outcome Scale scores. This finding supports a role for socioeconomic factors to affect discharge outcome and may help explain why the dual-eligible patients in our study, beneficiaries of public insurance plans (specifically Medicare plus Medicaid), had significantly decreased odds of discharge to home than all other beneficiaries.

Despite increased odds of complications and higher Clavien-Dindo Classifications among dual-eligible patients, our study found significantly shorter lengths of stay among dual-eligible beneficiaries compared to Medicaid patients. One possible explanation for this is the increased availability of skilled nursing facilities for dually insured patients compared to patients solely insured by Medicaid. Patients with Medicaid may run into issues with insurance eligibility at assisted living and skilled nursing facilities which may prolong the discharge process, thus increasing their overall length of stay. Results of a retrospective analysis by Fargen et al. [27] demonstrated shorter lengths of stay for privately insured patients therefore perhaps highlighting increased access to rehabilitation and skilled nursing facilities compared to Medicaid patients.

Limitations: The limitations of the present study include a lack of more nuanced insurance information and a follow-up period limited to prior to 2011. Given the limited insurance information provided, the authors designated anyone with both Medicare and Medicaid insurance as dual-eligible however, there is a need for follow-up studies looking at other insurance types such as individuals with both Medicare and private insurance (Medicare Advantage). Lastly, due to a lack of dual-insurance reporting in the National Inpatient Sample beyond the year 2011, we were unable to ascertain dual-eligible status beyond this year. However, it is important to note that the dual-eligible population has since increased with an average annual growth rate of $2.9 \%$, thus providing continual relevance to our analysis $[28,29]$. Nonetheless, additional studies are warranted to better understand the impact of dual-eligible status on hemorrhagic stroke outcomes.

\section{Conclusion}

This 10-year span cross-sectional study of dual-eligible patients following emergent hemorrhagic stroke found increased adverse outcomes in this population compared to other insured and uninsured groups, from lower odds of favorable discharge to increased odds of complications and in-hospital mortality. 
Adverse outcomes among dual-eligible beneficiaries highlight the need to uncover and address unknown sources of disparities to improve emergency treatment of hemorrhagic stroke in this population.

\section{Declarations}

\section{ACKNOWLEDGEMENTS}

We would like to thank Supporting Underrepresented Research and Generating Equity (SURGE) collaborators for their support; Kiara Corcoran Ruiz, Joseph Chen, Leila Paul, Praveen Rajaguru, Ashwin Veeramani, Polina Zmijewski, MD, and Thomas Carruthers, MD.

Funding: No funding applied to this work.

Conflict of Interest/Competing Interests: All the authors declare that they have nothing to disclose.

Availability of Data and Material: All data can be found online as the National Inpatient Sample is a publicly available database. A fee may apply.

Code Availability: Code available upon request.

Author Contributions: The study was conceived by Krissia Rivera Perla and Oliver Tang; study was coordinated by Youry Pierre-Louis and Krissia Rivera Perla. All authors were involved in interpretation of data for the work, drafting and revising for critically important intellectual content, and final approval of the version to be published.

Compliance with Ethical Standards: Study complied with ethical standards/institutional approval was obtained. The manuscript has not been published elsewhere and is not under consideration by another journal.

Ethical Approval: IRB deemed study exempt. The National Inpatient Sample is an anonymized publicly available database.

Consent to Participate: Not applicable as the National Inpatient Sample is an anonymized publicly available dataset.

Consent for Publication: All authors have consented to the publication of this manuscript.

\section{References}

1. Feigin VL. Stroke in developing countries: can the epidemic be stopped and outcomes improved? Lancet Neurol. 2007;6(2):94-7. doi:10.1016/S1474-4422(07)70007-8.

2. Ojaghihaghighi S, Vahdati SS, Mikaeilpour A, Ramouz A. Comparison of neurological clinical manifestation in patients with hemorrhagic and ischemic stroke. World J Emerg Med. 2017;8(1):34. doi:10.5847/wjem.j.1920-8642.2017.01.006. 
3. Chen S, Zeng L, Hu Z. Progressing haemorrhagic stroke: categories, causes, mechanisms and managements. J Neurol. 2014;261(11):2061-78. doi:10.1007/s00415-014-7291-1.

4. Unnithan AKA, Mehta P. Hemorrhagic Stroke. Accessed April 11, 2021. https://pubmed.ncbi.nlm.nih.gov/32644599/.

5. Kapral MK, Wang H, Mamdani M, Tu JV. Effect of socioeconomic status on treatment and mortality after stroke. Stroke. 2002;33(1):268-73. doi:10.1161/hs0102.101169.

6. Schoen $C$, DesRoches $C$ Uninsured and unstably insured: the importance of continuous insurance coverage. Heal Serv Res. Accessed April 11, 2021. https://pubmed.ncbi.nlm.nih.gov/10778809/.

7. James ML, Grau-Sepulveda MV, Olson DM, et al. Insurance status and outcome after intracerebral hemorrhage: Findings from get with the Guidelines-stroke. J Stroke Cerebrovasc Dis. 2014;23(2):283-92. doi:10.1016/j.jstrokecerebrovasdis.2013.02.016.

8. Ram P, Miah FT, Wyrick JM, Kalosza BA, Coritsidis GN. Outcomes in Critically III Patients With Traumatic Brain Injury: Ethnicity, Documentation, and Insurance Status. Crit Care Med. 2020;48(1):31-40. doi:10.1097/CCM.0000000000004043.

9. Schiraldi M, Patil CG, Mukherjee D, et al. Effect of insurance and racial disparities on outcomes in traumatic brain injury. J Neurol Surgery Part A Cent Eur Neurosurg. 2015;76(3):224-32. doi:10.1055/s-0034-1543958.

10. Chen H, Scarborough J, Zens T, Brummeyer B, Agarwal S, Haines KL. Race and Insurance Status as Predictors of Bicycle Trauma Outcome in Adults. J Surg Res. 2020;245:198-204. doi:10.1016/j.jss.2019.07.064.

11. Congressional Budget Office. Dual-Eligible Beneficiaries of Medicare and Medicaid: Characteristics, Health Care Spending, and Evolving Policies. 2013;(June 2013):45. http://www.cbo.gov/sites/default/files/cbofiles/attachments/44308_DualEligibles.pdf.

12. Shen JJ, Washington EL. Disparities in outcomes among patients with stroke associated with insurance status. Stroke. 2007;38(3):1010-6. doi:10.1161/01.STR.0000257312.12989.af.

13. HCUP-US NIS Overview. Accessed January 12. 2021. https://www.hcup-us.ahrq.gov/nisoverview.jsp.

14. McCormick PJ, Lin H, mo, Deiner SG, Levin MA. Validation of the All Patient Refined Diagnosis Related Group (APR-DRG). Risk of Mortality and Severity of Illness Modifiers as a Measure of Perioperative Risk. J Med Syst. 2018;42(5):81. doi:10.1007/s10916-018-0936-3.

15. Monterde D, Cainzos-Achirica M, Cossio-Gil Y, et al. Performance of comprehensive risk adjustment for the prediction of in-hospital events using administrative healthcare data: The queralt indices. Risk Manag Healthc Policy. 2020;13:271-83. doi:10.2147/RMHP.S228415.

16. Hall EC, Boyarsky BJ, Deshpande NA, et al. Perioperative complications after live-donor hepatectomy. JAMA Surg. 2014;149(3):288-91. doi:10.1001/jamasurg.2013.3835.

17. Dindo D, Demartines N, Clavien PA. Classification of surgical complications: A new proposal with evaluation in a cohort of 6336 patients and results of a survey. Ann Surg. 2004;240(2):205-13. doi:10.1097/01.sla.0000133083.54934.ae. 
18. Consumer Price I, 1913- | Federal Reserve Bank of Minneapolis. Accessed December 14, 2020. https://www.minneapolisfed.org/about-us/monetary-policy/inflation-calculator/consumer-priceindex-1913-.

19. Producing National HCUP Estimates - Accessible Version. Accessed November 12. 2020. https://hcup-us.ahrq.gov/tech_assist/nationalestimates/508_course/508course_2018.jsp.

20. Lai PMR, Dasenbrock H, Lin N, Du R. The impact of insurance status on the outcomes after aneurysmal subarachnoid hemorrhage. PLoS One. 2013;8(10). doi:10.1371/journal.pone.0078047.

21. Hobson C, Dortch J, Baslanti TO, et al. Insurance status is associated with treatment allocation and outcomes after subarachnoid hemorrhage. PLoS One. 2014;9(8). doi:10.1371/journal.pone.0105124.

22. McCutcheon BA, Chang DC, Marcus $L$, et al. Treatment biases in traumatic neurosurgical care: $A$ retrospective study of the Nationwide Inpatient Sample from 1998 to 2009. J Neurosurg. 2015;123(2):406-14. doi:10.3171/2015.3.JNS131356.

23. Gardizi E, Hanks RA, Millis SR, Figueroa MJ. Comorbidity and insurance as predictors of disability after traumatic brain injury. Arch Phys Med Rehabil. 2014;95(12):2396-401. doi:10.1016/j.apmr.2014.06.004.

24. Dasenbrock HH, Bartolozzi AR, Gormley WB, Frerichs KU, Aziz-Sultan MA, Du R. Clostridium difficile Infection after Subarachnoid Hemorrhage: A Nationwide Analysis. Neurosurgery. 2016;78(3):412-20. doi:10.1227/NEU.0000000000001065.

25. Janus TJ, Smith HL, Chigazola A, Wortman MR, Sidwell RA, Piper JG. Hospital discharge destinations for Hispanic and non-Hispanic white patients treated for traumatic brain injury. J Trauma Nurs. 2013;20(2). doi:10.1097/JTN.0b013e318296003a.

26. Strickland BA, Mert M, Ravina K, et al. Discrepancy in Neurologic Outcomes Following Aneurysmal Subarachnoid Hemorrhage as a Function of Socioeconomic Class. World Neurosurg. 2020;138:e787-94. doi:10.1016/j.wneu.2020.03.087.

27. Fargen KM, Neal D, Blackburn SL, Hoh BL, Rahman M. Health disparities and stroke: The influence of insurance status on the prevalence of patient safety indicators and hospital-acquired conditions. J Neurosurg. 2015;122(4):870-5. doi:10.3171/2014.12.JNS14646.

28. Medicare-Medicaid Coordination Office. Data Analysis Brief: Medicare-Medicaid Dual Enrollment from 2006 through 2018.; 2016. Accessed March 13, 2021. https://www.cms.gov/MedicareMedicaid-Coordination/Medicare-and-Medicaid-.

29. Centers for Medicare and Medicaid. People Dually Eligible for Medicare and Medicaid.

\section{Tables}


Table 1

Demographics

\begin{tabular}{|c|c|c|c|c|c|}
\hline No. (\%) & $\begin{array}{l}\text { Dual-Eligible } \\
\text { [n=28,114] }\end{array}$ & $\begin{array}{l}\text { Medicare } \\
{[n=124,160]}\end{array}$ & $\begin{array}{l}\text { Medicaid } \\
{[n=29,507]}\end{array}$ & $\begin{array}{l}\text { Private } \\
\text { [n }=225,767]\end{array}$ & $\begin{array}{l}\text { No Charge } \\
{[n=3,073]}\end{array}$ \\
\hline $\operatorname{Sex}(F)$ & $\begin{array}{l}16,698 \\
(59.4 \%)\end{array}$ & $\begin{array}{l}62,769 \\
(50.6 \%)\end{array}$ & $\begin{array}{l}10,126 \\
(34.3 \%)\end{array}$ & $\begin{array}{l}104,357 \\
(46.2 \%)\end{array}$ & $854(27.8 \%)$ \\
\hline Age (Mean [SD]) & $73.4(14.9)$ & $77.9(11.2)$ & $46.2(16.3)$ & $67.3(20.4)$ & $47.6(18.2)$ \\
\hline \multicolumn{6}{|l|}{ Race } \\
\hline White & $\begin{array}{l}18,093 \\
(64.4 \%)\end{array}$ & $\begin{array}{l}103,281 \\
(83.2 \%)\end{array}$ & $\begin{array}{l}16,791 \\
(56.9 \%)\end{array}$ & $\begin{array}{l}187,262 \\
(82.9 \%)\end{array}$ & $\begin{array}{l}1,915 \\
(62.3 \%)\end{array}$ \\
\hline Black & $\begin{array}{l}4,200 \\
(14.9 \%)\end{array}$ & $10,327(8.3 \%)$ & $\begin{array}{l}6,466 \\
(21.9 \%)\end{array}$ & $15,251(6.8 \%)$ & $345(11.2 \%)$ \\
\hline Hispanic & $\begin{array}{l}3,366 \\
(12.0 \%)\end{array}$ & $5,079(4.1 \%)$ & $\begin{array}{l}3,687 \\
(12.5 \%)\end{array}$ & $11,437(5.1 \%)$ & 600 (19.5\%) \\
\hline Other & $2,455(8.7 \%)$ & $5,472(4.4 \%)$ & $2,562(8.7 \%)$ & $11,817(5.2 \%)$ & $213(6.9 \%)$ \\
\hline \multicolumn{6}{|l|}{ Income (Percentile) } \\
\hline $0-25$ th & $\begin{array}{l}11,147 \\
(39.6 \%)\end{array}$ & $\begin{array}{l}34,248 \\
(27.6 \%)\end{array}$ & $\begin{array}{l}12,518 \\
(42.4 \%)\end{array}$ & $\begin{array}{l}47,886 \\
(21.2 \%)\end{array}$ & $\begin{array}{l}1,162 \\
(37.8 \%)\end{array}$ \\
\hline 26-50th & $\begin{array}{l}6,771 \\
(24.1 \%)\end{array}$ & $\begin{array}{l}31,732 \\
(25.6 \%)\end{array}$ & $\begin{array}{l}7,439 \\
(25.2 \%)\end{array}$ & $\begin{array}{l}52,777 \\
(23.4 \%)\end{array}$ & $740(24.1 \%)$ \\
\hline 51-75th & $\begin{array}{l}5,741 \\
(20.4 \%)\end{array}$ & $\begin{array}{l}28,449 \\
(22.9 \%)\end{array}$ & $\begin{array}{l}5,739 \\
(19.4 \%)\end{array}$ & $\begin{array}{l}56,390 \\
(25.0 \%)\end{array}$ & $573(18.6 \%)$ \\
\hline 76-100th & $\begin{array}{l}4,454 \\
(15.8 \%)\end{array}$ & $\begin{array}{l}29,730 \\
(23.9 \%)\end{array}$ & $\begin{array}{l}3,810 \\
(12.9 \%)\end{array}$ & $\begin{array}{l}68,714 \\
(30.4 \%)\end{array}$ & 598 (19.5\%) \\
\hline \multicolumn{6}{|l|}{ Bleed Type } \\
\hline Epidural & $435(1.5 \%)$ & $1,341(1.1 \%)$ & $854(2.9 \%)$ & $3,864(1.7 \%)$ & $117(3.8 \%)$ \\
\hline Subdural & $\begin{array}{l}17,057 \\
(60.7 \%)\end{array}$ & $\begin{array}{l}73,967 \\
(59.6 \%)\end{array}$ & $\begin{array}{l}13,359 \\
(45.3 \%)\end{array}$ & $\begin{array}{l}116,277 \\
(51.5 \%)\end{array}$ & $\begin{array}{l}1,440 \\
(46.9 \%)\end{array}$ \\
\hline Subarachnoid & $\begin{array}{l}6,210 \\
(22.1 \%)\end{array}$ & $\begin{array}{l}29,688 \\
(23.9 \%)\end{array}$ & $\begin{array}{l}9,673 \\
(32.8 \%)\end{array}$ & $\begin{array}{l}67,125 \\
(29.7 \%)\end{array}$ & $\begin{array}{l}1,071 \\
(34.9 \%)\end{array}$ \\
\hline Intracerebral & $\begin{array}{l}4,411 \\
(15.7 \%)\end{array}$ & $\begin{array}{l}19,163 \\
(15.4 \%)\end{array}$ & $\begin{array}{l}5,621 \\
(19.0 \%)\end{array}$ & $\begin{array}{l}38,501 \\
(17.1 \%)\end{array}$ & $445(14.5 \%)$ \\
\hline Procedure (Yes) & $1,247(4.4 \%)$ & $5,568(4.5 \%)$ & $2,693(9.1 \%)$ & $12,260(5.4 \%)$ & $186(6.1 \%)$ \\
\hline \multicolumn{6}{|c|}{ APR-DRG Risk of Mortality } \\
\hline Minor & $\begin{array}{l}6,015 \\
(21.4 \%)\end{array}$ & $\begin{array}{l}25,542 \\
(20.6 \%)\end{array}$ & $\begin{array}{l}13,603 \\
(46.1 \%)\end{array}$ & $\begin{array}{l}74,927 \\
(33.2 \%)\end{array}$ & $\begin{array}{l}1,650 \\
(53.7 \%)\end{array}$ \\
\hline
\end{tabular}




\begin{tabular}{|c|c|c|c|c|c|}
\hline No. (\%) & $\begin{array}{l}\text { Dual-Eligible } \\
\text { [n=28,114] }\end{array}$ & $\begin{array}{l}\text { Medicare } \\
{[n=124,160]}\end{array}$ & $\begin{array}{l}\text { Medicaid } \\
{[n=29,507]}\end{array}$ & $\begin{array}{l}\text { Private } \\
{[n=225,767]}\end{array}$ & $\begin{array}{l}\text { No Charge } \\
{[n=3,073]}\end{array}$ \\
\hline Moderate & $\begin{array}{l}12,144 \\
(43.2 \%)\end{array}$ & $\begin{array}{l}54,616 \\
(44.0 \%)\end{array}$ & $\begin{array}{l}5,820 \\
(19.7 \%)\end{array}$ & $\begin{array}{l}79,245 \\
(35.1 \%)\end{array}$ & $571(18.6 \%)$ \\
\hline Major & $\begin{array}{l}5,679 \\
(20.2 \%)\end{array}$ & $\begin{array}{l}23,826 \\
(19.2 \%)\end{array}$ & $\begin{array}{l}5,187 \\
(17.6 \%)\end{array}$ & $\begin{array}{l}39,271 \\
(17.4 \%)\end{array}$ & $465(15.1 \%)$ \\
\hline Extreme & $\begin{array}{l}4,276 \\
(15.2 \%)\end{array}$ & $\begin{array}{l}20,177 \\
(16.3 \%)\end{array}$ & $\begin{array}{l}4,897 \\
(16.6 \%)\end{array}$ & $\begin{array}{l}32,324 \\
(14.3 \%)\end{array}$ & $387(12.6 \%)$ \\
\hline \multicolumn{6}{|c|}{ APR-DRG Severity of Illness } \\
\hline Minor & $\begin{array}{l}3,930 \\
(14.0 \%)\end{array}$ & $\begin{array}{l}20,822 \\
(16.8 \%)\end{array}$ & $\begin{array}{l}6,362 \\
(21.6 \%)\end{array}$ & $\begin{array}{l}46,216 \\
(20.5 \%)\end{array}$ & 919 (29.9\%) \\
\hline Moderate & $\begin{array}{l}10,415 \\
(37.0 \%)\end{array}$ & $\begin{array}{l}44,160 \\
(35.6 \%)\end{array}$ & $\begin{array}{l}8,695 \\
(29.5 \%)\end{array}$ & $\begin{array}{l}78,488 \\
(34.8 \%)\end{array}$ & 979 (31.9\%) \\
\hline Major & $\begin{array}{l}9,388 \\
(33.4 \%)\end{array}$ & $\begin{array}{l}41,237 \\
(33.2 \%)\end{array}$ & $\begin{array}{l}7,855 \\
(26.6 \%)\end{array}$ & $\begin{array}{l}67,483 \\
(29.9 \%)\end{array}$ & $678(22.1 \%)$ \\
\hline Extreme & $\begin{array}{l}4,381 \\
(15.6 \%)\end{array}$ & $\begin{array}{l}17,941 \\
(14.4 \%)\end{array}$ & $\begin{array}{l}6,595 \\
(22.4 \%)\end{array}$ & $\begin{array}{l}33,579 \\
(14.9 \%)\end{array}$ & $497(16.2 \%)$ \\
\hline Hospital (Urban) & $\begin{array}{l}25,571 \\
(92.0 \%)\end{array}$ & $\begin{array}{l}115,180 \\
(93.9 \%)\end{array}$ & $\begin{array}{l}28,310 \\
(97.2 \%)\end{array}$ & $\begin{array}{l}211,683 \\
(94.7 \%)\end{array}$ & $\begin{array}{l}2,909 \\
(98.8 \%)\end{array}$ \\
\hline \multicolumn{6}{|l|}{ Hospital Region } \\
\hline Northeast & $\begin{array}{l}10,501 \\
(37.4 \%)\end{array}$ & $\begin{array}{l}36,841 \\
(29.7 \%)\end{array}$ & $\begin{array}{l}9,942 \\
(33.7 \%)\end{array}$ & $\begin{array}{l}72,280 \\
(32.0 \%)\end{array}$ & $\begin{array}{l}1,036 \\
(33.7 \%)\end{array}$ \\
\hline Midwest & $\begin{array}{l}6,392 \\
(22.7 \%)\end{array}$ & $\begin{array}{l}30,945 \\
(24.9 \%)\end{array}$ & $\begin{array}{l}7,009 \\
(23.8 \%)\end{array}$ & $\begin{array}{l}60,582 \\
(26.8 \%)\end{array}$ & $486(15.8 \%)$ \\
\hline South & $\begin{array}{l}9,449 \\
(33.6 \%)\end{array}$ & $\begin{array}{l}47,431 \\
(38.2 \%)\end{array}$ & $\begin{array}{l}10,248 \\
(34.7 \%)\end{array}$ & $\begin{array}{l}73,991 \\
(32.8 \%)\end{array}$ & $958(31.2 \%)$ \\
\hline West & $1,772(6.3 \%)$ & $8,942(7.2 \%)$ & $2,308(7.8 \%)$ & $18,914(8.4 \%)$ & $593(19.3 \%)$ \\
\hline
\end{tabular}


Table 2

Outcomes: Descriptive

\begin{tabular}{|c|c|c|c|c|c|}
\hline No. (\%) & $\begin{array}{l}\text { Dual-Eligible } \\
{[n=28,114]}\end{array}$ & $\begin{array}{l}\text { Medicare } \\
{[n=124,160]}\end{array}$ & $\begin{array}{l}\text { Medicaid } \\
{[n=29,507]}\end{array}$ & $\begin{array}{l}\text { Private } \\
{[n=225,767]}\end{array}$ & $\begin{array}{l}\text { No Charge } \\
{[n=3,073]}\end{array}$ \\
\hline Died & $\begin{array}{l}3,098 \\
(11.0 \%)\end{array}$ & $\begin{array}{l}16,046 \\
(13.0 \%)\end{array}$ & $2,557(8.7 \%)$ & $\begin{array}{l}24,158 \\
(10.7 \%)\end{array}$ & $177(5.8 \%)$ \\
\hline Complications & $\begin{array}{l}7,768 \\
(27.6 \%)\end{array}$ & $\begin{array}{l}32,805 \\
(26.4 \%)\end{array}$ & $\begin{array}{l}7,483 \\
(25.4 \%)\end{array}$ & $\begin{array}{l}51,665 \\
(22.9 \%)\end{array}$ & $703(22.9 \%)$ \\
\hline Respiratory & $\begin{array}{l}3,129 \\
(11.1 \%)\end{array}$ & $\begin{array}{l}13,570 \\
(10.9 \%)\end{array}$ & $\begin{array}{l}4,504 \\
(15.3 \%)\end{array}$ & $\begin{array}{l}24,254 \\
(10.7 \%)\end{array}$ & $394(12.8 \%)$ \\
\hline Cardiac & $442(1.6 \%)$ & $2,100(1.7 \%)$ & $498(1.7 \%)$ & $3,546(1.6 \%)$ & $51(1.7 \%)$ \\
\hline Gastrointestinal & $295(1.0 \%)$ & $1,048(0.8 \%)$ & $290(1.0 \%)$ & $1,710(0.8 \%)$ & $5(0.2 \%)$ \\
\hline Infection & $\begin{array}{l}4,918 \\
(17.5 \%)\end{array}$ & $\begin{array}{l}20,323 \\
(16.4 \%)\end{array}$ & $\begin{array}{l}3,521 \\
(11.9 \%)\end{array}$ & $\begin{array}{l}28,612 \\
(12.7 \%)\end{array}$ & $320(10.4 \%)$ \\
\hline Neurologic & $301(1.1 \%)$ & 1,328 (1.1\%) & 294 (1.0\%) & 2,393 (1.1\%) & $43(1.4 \%)$ \\
\hline Other & $95(0.3 \%)$ & $343(0.3 \%)$ & $226(0.8 \%)$ & $813(0.4 \%)$ & $24(0.8 \%)$ \\
\hline \multicolumn{6}{|c|}{ Clavien-Dindo Classification } \\
\hline 1 & $737(2.6 \%)$ & $3,256(2.6 \%)$ & $948(3.2 \%)$ & $7,053(3.1 \%)$ & $122(4.0 \%)$ \\
\hline 2 & $\begin{array}{l}4,082 \\
(14.5 \%)\end{array}$ & $\begin{array}{l}16,890 \\
(13.6 \%)\end{array}$ & $2,451(8.3 \%)$ & $\begin{array}{l}23,292 \\
(10.3 \%)\end{array}$ & $247(8.0 \%)$ \\
\hline 3 & $119(0.4 \%)$ & $342(0.3 \%)$ & $211(0.7 \%)$ & $918(0.4 \%)$ & $28(0.9 \%)$ \\
\hline 4 & 2,247 (8.0\%) & $9,436(7.6 \%)$ & $\begin{array}{l}3,186 \\
(10.8 \%)\end{array}$ & $\begin{array}{l}15,963 \\
(7.1 \%)\end{array}$ & 264 (8.6\%) \\
\hline $\begin{array}{l}\text { Favorable } \\
\text { Discharge }\end{array}$ & $\begin{array}{l}9,764 \\
(35.1 \%)\end{array}$ & $\begin{array}{l}47,812 \\
(38.8 \%)\end{array}$ & $\begin{array}{l}17,135 \\
(60.1 \%)\end{array}$ & $\begin{array}{l}110,409 \\
(49.3 \%)\end{array}$ & $\begin{array}{l}2,172 \\
(73.0 \%)\end{array}$ \\
\hline $\begin{array}{l}\text { LOS (days) [mean } \\
(95 \% \mathrm{Cl})]\end{array}$ & $7.3[7.0-7.5]$ & $6.8[6.6-7.0]$ & $\begin{array}{l}11.0[10.3- \\
11.7]\end{array}$ & 7.1 [6.9-7.3] & $8.0[6.8-9.1]$ \\
\hline $\begin{array}{l}\text { Cost (U.S dollars) } \\
\text { [mean }(95 \% \mathrm{Cl}) \text { ] }\end{array}$ & $\begin{array}{l}\$ 13,948 \\
{[\$ 13,119-} \\
\$ 14,777]\end{array}$ & $\begin{array}{l}\$ 13,188 \\
{[\$ 12,586-} \\
\$ 13,790]\end{array}$ & $\begin{array}{l}\$ 23,546 \\
{[\$ 21,935-} \\
\$ 25,157]\end{array}$ & $\begin{array}{l}\$ 15,562 \\
{[\$ 14,872-} \\
\$ 16,252]\end{array}$ & $\begin{array}{l}\$ 19,461 \\
{[\$ 16,431-} \\
\$ 22,490]\end{array}$ \\
\hline
\end{tabular}

Table 3. Outcomes: Dual-Eligible vs. Each Insurance Group 


\begin{tabular}{|c|c|c|c|c|}
\hline Dual-Eligible vs. & Medicare & Medicaid & Private & No Charge \\
\hline \multicolumn{5}{|l|}{ Mortality } \\
\hline OR $(95 \% \mathrm{Cl})$ & $\begin{array}{l}0.92[0.82- \\
1.04)]\end{array}$ & $\begin{array}{l}1.17[0.97- \\
1.42]\end{array}$ & $\begin{array}{l}0.90[0.81- \\
0.995]^{*}\end{array}$ & $\begin{array}{l}1.61[1.04- \\
2.49]^{\star}\end{array}$ \\
\hline \multicolumn{5}{|l|}{ Complication } \\
\hline OR $(95 \% \mathrm{Cl})$ & $\begin{array}{l}0.98[0.91- \\
1.06]\end{array}$ & $\begin{array}{l}1.23[1.11- \\
1.37]^{\star \star \star}\end{array}$ & $\begin{array}{l}1.19[1.11- \\
1.28]^{\star \star \star}\end{array}$ & $1.01[0.80-1.28]$ \\
\hline \multicolumn{5}{|c|}{ Clavien-Dindo Classification } \\
\hline OR $(95 \% \mathrm{Cl})$ & $1.01[0.93-1.09]$ & $\begin{array}{l}1.21[1.08- \\
1.35]^{\star \star \star}\end{array}$ & $\begin{array}{l}1.21[1.13- \\
1.30]^{\star \star \star}\end{array}$ & $1.01[0.77-1.31]$ \\
\hline \multicolumn{5}{|l|}{ Favorable Discharge } \\
\hline OR $(95 \% \mathrm{Cl})$ & $\begin{array}{l}0.86[0.79- \\
0.92)^{\star \star \star}\end{array}$ & $\begin{array}{l}0.32[0.28- \\
0.35]^{\star \star \star}\end{array}$ & $\begin{array}{l}0.56[0.52- \\
0.60]^{\star \star \star}\end{array}$ & $\begin{array}{l}0.21[0.16- \\
0.29]^{\star \star \star}\end{array}$ \\
\hline \multicolumn{5}{|l|}{ Length of Stay } \\
\hline $\begin{array}{l}\text { - Coefficient (95\% } \\
\mathrm{Cl})\end{array}$ & $\begin{array}{l}1.00[0.97- \\
1.04]\end{array}$ & $\begin{array}{l}0.82[0.78- \\
0.86]^{\star \star \star}\end{array}$ & $\begin{array}{l}0.99[0.96- \\
1.02]\end{array}$ & $0.99[0.89-1.09]$ \\
\hline \multicolumn{5}{|l|}{ Cost } \\
\hline $\begin{array}{l}\text { - Coefficient (95\% } \\
\mathrm{Cl})\end{array}$ & $\begin{array}{l}0.95[0.92- \\
0.99]^{\star}\end{array}$ & $\begin{array}{l}0.76[0.73- \\
0.80]^{\star \star \star}\end{array}$ & $\begin{array}{l}0.88[0.85- \\
0.90]^{\star \star \star}\end{array}$ & $\begin{array}{l}0.82[0.75- \\
0.89]^{\star \star \star *}\end{array}$ \\
\hline
\end{tabular}

\section{Figures}




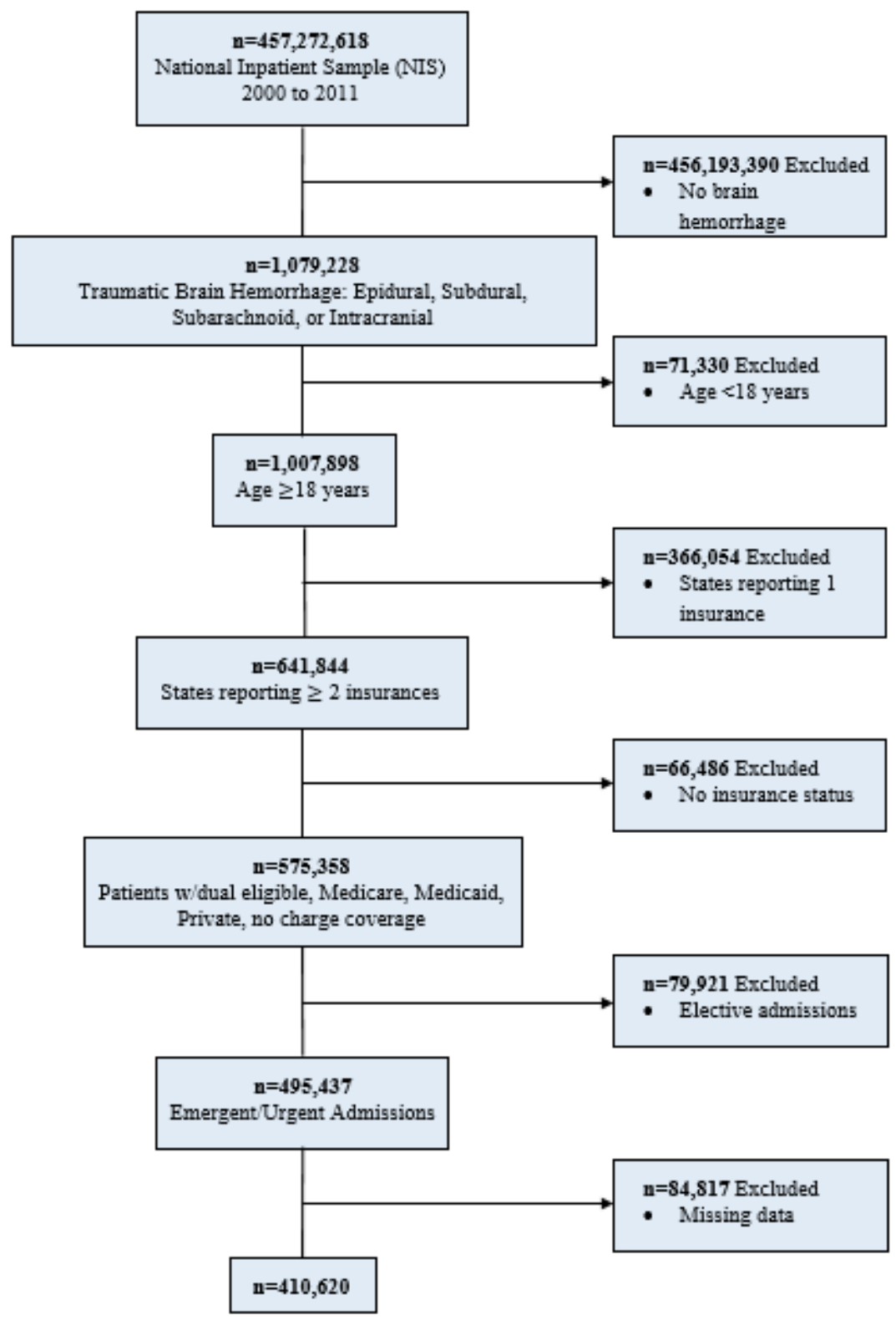

\section{Figure 1}

Study Flow Diagram 


\section{Intracranial Hemorrhage Categories}

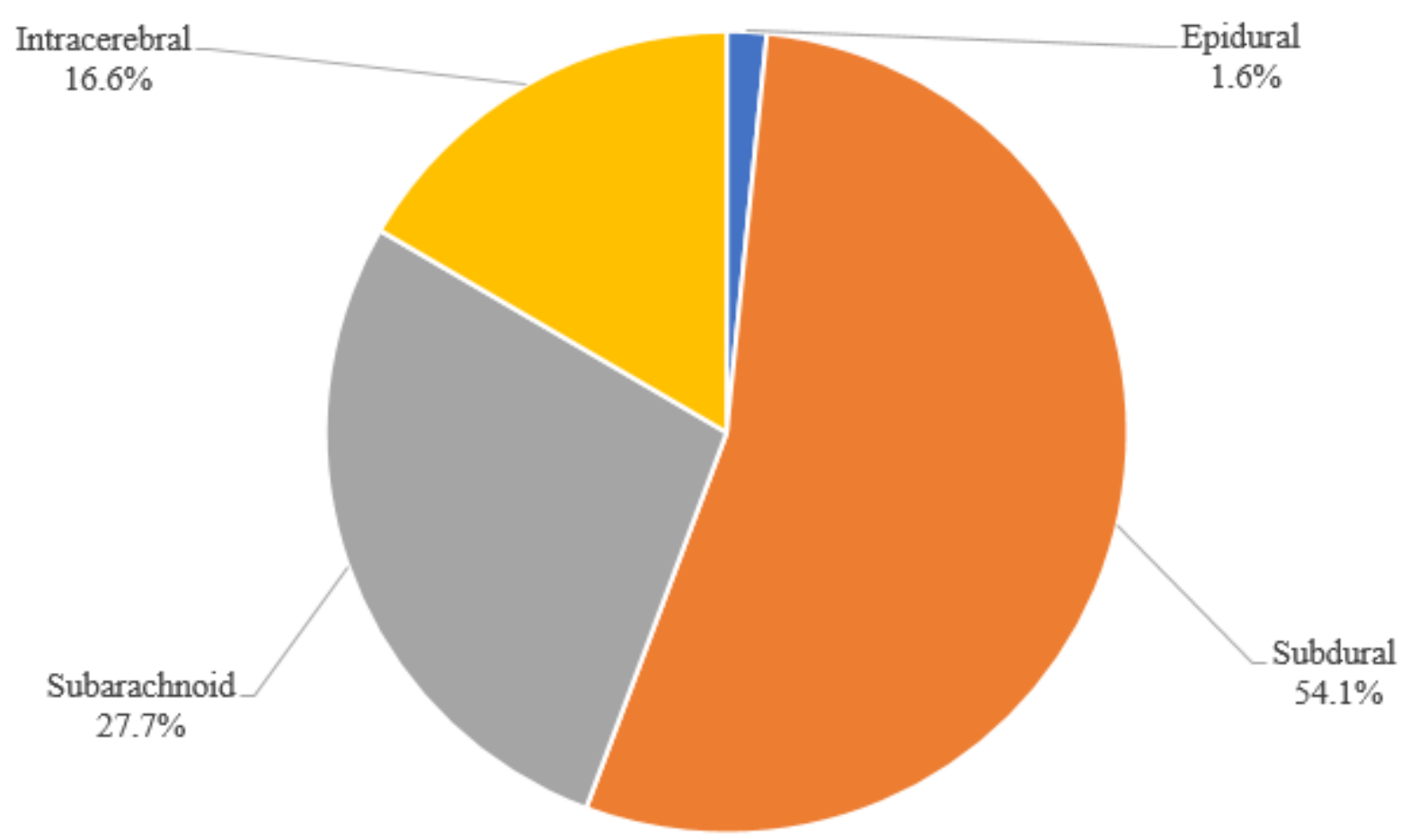

Figure 2

Categories for Intracranial Hemorrhage due to TBI

\section{Supplementary Files}

This is a list of supplementary files associated with this preprint. Click to download.

- SupplementaryBrainHemorrhage.docx 